\title{
IS THERE AN ASSOCIATION BETWEEN AUTOANTIBODIES INDUCTION AND LOSS OF THERAPEUTIC EFFICACY IN PATIENTS WITH AXIAL SPONDYLOARTHRITIS AND PSORIATIC ARTHRITIS TREATED WITH ANTI-TNF- $\alpha$ AGENTS?
}

\author{
Ana Martins ${ }^{1, \star}$, Daniela Oliveira ${ }^{1}$, Frederico Rajão Martins ${ }^{2}$, Filipe Oliveira Pinheiro ${ }^{1}$, Maria Seabra Rato ${ }^{1}$, Diogo Guimarães \\ Fonseca ${ }^{3}$, Salomé Garcia ${ }^{1}$, Bruno Miguel Fernandes ${ }^{1}$, Sofia Pimentaํ․ Miguel Bernardes ${ }^{1}$, Lúcia Costa ${ }^{1}$ \\ 1.Centro Hospitalar Universitário de São João, Porto (Douro Litoral), Portugal; 2.Centro Hospitalar Universitário do Algarve, Faro (Algarve), \\ Portugal; 3.Centro Hospitalar de Vila Nova de Gaia/Espinho, Vila Nova de Gaia (Douro Litoral), Portugal. \\ *Corresponding author: anaigmartins.med@gmail.com
}

\section{BACKGROUND}

Induction of autoantibodies is frequently observed in patients treated with a tumor necrosis factor alpha (TNF-a) blocker. However, it is unknown whether the induction of these autoantibodies affects the pharmacokinetics and bioavailability of biotherapy and, consequently, reduces the efficacy and safety of the drug.

\section{METHODS}

We performed a retrospective analysis of patients with axial spondyloarthritis (axSpA) and psoriatic arthritis (PsA) treated in our university hospital with a TNF- $\alpha$ blocker as first biologic agent. We analyzed the autoantibodies induction rate and investigated the influence of autoantibodies in therapeutic efficacy after 12 (T12) and 24 (T24) months of therapy. Clinical evaluation, laboratory findings and disease activity and functional scores were collected from reuma.pt and medical records. Patients with positive ANA (titer $>1 / 100$ ) prior to anti-TNF- $\alpha$ therapy were excluded. Continuous and categorical variables were analyzed using a t-test and a chi-square test, respectively. P-value $<0.05$ was considered statistically significant.

\section{RESULTS}

In axSpA group, 236 patients were included. Positive ANA were found in $16.9 \%$ at T12 and $26.3 \%$ at T24 and positive anti-dsDNA in 3.4\% at T12 and 3.8\% at T24, with similar conversion rates between different anti-TNF drugs and no significant gender difference. Ankylosing spondylitis disease activity score-C-reactive protein (ASDAS-CRP) was significantly higher in axSpA patients with ANA at T12 ( $p=0.047)$. However, no difference was found in the others disease activity and functional scores at T12. At T24, no significant difference, including ASDAS-CRP, was found. Also, no significant difference was found in patients with and without anti-dsDNA. In PsA group, 94 patients were included. Positive ANA were found in $14.9 \%$ at T12 and $21.3 \%$ at T24 and positive anti-dsDNA in $2.1 \%$ at T12 and 3.2\% at T24. When comparing the groups with and without ANA and with and without anti-dsDNA at T12 and T24, no significant difference in disease activity and functional scores was found.

\section{CONCLUSION}

This study revealed high rates of serology conversion, similar to the rates described before. The authors found that ASDAS-CRP was higher in axSpA patients with ANA after 12 months of therapy. However, this difference was no longer evident after 24 months. No other significant difference was found. We consider that the induction of autoantibodies may interfere with the response to antiTNF- $\alpha$ therapy in a short and initial period of time. Long-term follow-up data are lacking to say whether that influence will disappear consistently over the long run, as we observed after 12 months of therapy. However, we can state that, a priori, seroconversion should not lead to treatment suspension because of concerns about loss of efficacy.

\section{KEYWORDS}

Autoantibodies induction, Anti-TNF- agents, Therapeutic efficacy, Axial spondyloarthritis, Psoriatic arthritis. 